\title{
Perceived Barriers to Weight Management: A Qualitative Study on Overweight and Obese Women in Shiraz, Iran
}

mohadese borazjani

Shiraz University of Medical Sciences https://orcid.org/0000-0001-9563-8581

maryam amini

Shahid Beheshti University of Medical Sciences School of Nutrition and Food Technology

Shiva Faghih ( $\nabla$ shivafaghih@gmail.com )

Research article

Keywords: Obese, Weight-loss, barriers, women

Posted Date: June 25th, 2020

DOI: https://doi.org/10.21203/rs.3.rs-32630/v1

License: @ (i) This work is licensed under a Creative Commons Attribution 4.0 International License.

Read Full License 


\section{Abstract}

Background: Obesity is among the most important health challenge, with an increasing incidence in current century. It is considered as an important factor lead to social unacceptability. Almost in all societies women are more careful and sensitive about their beauty and appearance than men. The purpose of this study was to assess perceived barriers to weight- loss programs among women with obesity in Shiraz.

Method: This qualitative study was conducted using eight semi-structured focus group discussions (FGDs) among 48 women and seven in-depth interviews with key informants. All eligible participants for FGDs were selected through a public call in Shiraz.

Results: Dietary, socio-cultural, supportive- psychological and economic issues were identified as the main barriers to weight-loss programs.

Conclusion: Data collected from the individual and group interviews provided extensive information on the strengths and weaknesses of dietary programs. The results of this study can be used to improve the services for obese and overweight people as well as expanding the knowledge of dietitians for developing more efficient weight-loss programs.

\section{Background:}

The increasing rate of obesity is a critical public health challenge worldwide. According to the World Health Organization (WHO) in 2014 more than 650 million adults around 18 years and older, were obese (1). Based on the latest WHO estimates in European Union countries, overweight affects $30-70 \%$ and obesity affects $10-30 \%$ of adults (2).

In Iran the prevalence of overweight and obesity among men and women is $42.8 \%$ and $57.0 \%$ respectively (3).

Obesity is a chronic, progressive disease that is difficult to treat and is associated with many harmful health effects like diabetes, hypertension, dyslipidemia, and cardiovascular diseases. Sustained weight loss is associated with prevention, alleviation and resolution of many obesity related comorbidities $(4,5)$.. Studies have indicated that obesity effects on individuals' health and their psychological state. The analysis emphasizes the role of obesity in depression, anxiety, body dissatisfaction, and low self-esteem (6).

To combat the mentioned problem, it is necessary to find proper strategies to reduce the rate of obesity and overweight. A large number of weight-loss programs, which combine diet, physical activity and behavioral change programs are effective only in short term and it is difficult for individuals to maintain a diet and keep the lost weight (7). It has been shown that 90 to $95 \%$ of obese individuals, who manage significant weight loss, will regain their weight over 3 to 5 year follow ups (8). 
Several investigations studied the perceived barriers to weight-loss programs such as poor socioeconomic conditions, mental and psychological problems and poor knowledge about weight loss and diets $(9,10)$. Regarding the effects of obesity on physical and mental health, in the current study we aimed to explore the reasons which brings about failure to maintain the weight-loss programs in women.

\section{Methods:}

Study design and participants:

In the current study both, quantitative and qualitative data were collected. To collect quantitative data height, weight, waist circumference and hip circumference were measured. To acquire a deep awareness of the issue in qualitative study a total of seven in-depth interviews with experts and eight focus group discussions (FGDs) with obese women were held.

The participants in focus group discussions filled out a demographic questionnaire at study entry. For FGDs a topic guide was prepared (Table 1). The guide included 13 questions designed according to the purpose of the study and participant groups. Out of the 13 questions, the first 5 ones were ice-breaking questions. Each question also was followed by some probing questions and the content of the topic guide was seen and approved by a group of experts including professors in nutrition.

Table 1

- TOPIC GUIDE used for FGDs and in-depth interviews

\section{Number QUESTIONS}

$1 \quad$ What is your idea about obesity and over weight?

$2 \quad$ What do you think about weight loss?

3 Do you think diets are effective for weight loss?

$4 \quad$ What are the benefits of following a weight loss diet?

$5 \quad$ What are the disadvantages of following a weight loss diet?

$6 \quad$ What are the barriers to obtaining a weight loss diet?

7 Is there a positive effect on the psychological support (from family and friens)of those who are on a diet?

$8 \quad$ Does the society have a supporting role in the success of weight loss diets?

9 Do you think the economic status of the family affects the success of a weight loss diet?

10 Do you think that one's socio-occupational status has an impact on the success of the diet?

11 Do you think long-term adherence to weight loss diets is harmful to health?

12 Explain any other comments about weight loss diets. 
Participants in the group discussion sessions included 48 women, aged between 18 and 55 years old, single and/or married, with different educational and occupational levels, which were selected based on the inclusion criteria of the applicants (Table2,3). They were invited through a public call in local newspaper in Shiraz, Iran. Each FGD was conducted with 5-8 participants and lasted for 45-60 minutes. The research team for FGDs was included of a coordinator and two note-takers, who were all nutritionists. FGD sessions were held in a quiet area in the conference hall of Imam Reza clinic in Shiraz, and all interviews were recorded with interviewee's permission. At the end of the sessions, anthropometric and demographic data were measured and some gifts (included kitchen scale and scale) were given to participants.

Table 2

mean anthropometric measurement of women participating in our FGDs.

\begin{tabular}{|lllllll|}
\hline & Age group & N & BMI & WC & HC & WHtR \\
\hline 1 & $18-25$ & 10 & 26.8 & 91.8 & 108.8 & 0.85 \\
\hline 2 & $26-30$ & 10 & 28.13 & 97.5 & 111.3 & 0.87 \\
\hline 3 & $31-35$ & 8 & 29.02 & 96.3 & 108.8 & 0.88 \\
\hline 4 & $36-40$ & 2 & 27.2 & 90.5 & 102.5 & 0.88 \\
\hline 5 & $41-45$ & 5 & 27.9 & 99 & 109.2 & 0.9 \\
\hline 6 & $46-50$ & 7 & 30.9 & 98 & 114.1 & 0.9 \\
\hline 7 & $51-55$ & 6 & 32.1 & 103 & 118.1 & 0.87 \\
\hline total & $18-55$ & 48 & 28.8 & 96.5 & 110.4 & 0.87 \\
\hline
\end{tabular}

Table 3

- Characteristics of women Participating in our FGDs.

\begin{tabular}{|lll|}
\hline VARIABLE & & N \\
\hline EDUCATION LEVEL & Diploma and less & 15 \\
\cline { 2 - 2 } & Associated degree & 3 \\
\cline { 2 - 2 } & Bachelor of science & 23 \\
\cline { 2 - 2 } Marital status & Master of science & 7 \\
\hline & YES & 32 \\
\hline
\end{tabular}

Then, we select seven key informants who were familiar with the field of nutrition and also well reputed on their own expertise. The interviews were hold in their offices and took them about one hour. They 
included two psychologists, two nutritionists, two people with obesity and one sociologist. In-depth interviews were coordinated by the chief researcher with the aid of topic guide.

\section{Data Analysis:}

Semi-structured interviews were analyzed by thematic analysis.

The MAXQDA11 software was used to sort and categorize the data. In the first step, interview file was transferred to the software, and in the next step, primary codes were extracted from the data. Then repeated codes were removed and the similar codes were merged to make emerging themes and categories, respectively. Themes and categories were classified in broader codes and finally the four main barriers were identified based on the main objective of study(Table4,at the end of the manuscript). 
Table 4

Second- and first-level themes identified through thematic analysis in eight FGDs.

\begin{tabular}{|c|c|}
\hline Main barriers & Subgroups \\
\hline \multirow[t]{9}{*}{ Dietary barriers } & - Food taste \\
\hline & - Diet and satiety \\
\hline & - Length of effect \\
\hline & - Restricted access to food \\
\hline & - Time restriction \\
\hline & - Weight gain \\
\hline & - Repetitive program \\
\hline & - Hard-to-follow \\
\hline & - Health problems \\
\hline \multirow[t]{9}{*}{ Social and cultural barriers } & - Lack of healthy surroundings \\
\hline & - Lack of social awareness about obesity \\
\hline & - Lack of urban facilities \\
\hline & - Role of party and traveling in obesity \\
\hline & - Stigmatization \\
\hline & - Being employed \\
\hline & - Maternal role \\
\hline & - Eating outdoors \\
\hline & - Decrease efficiency for studying \\
\hline \multirow{4}{*}{$\begin{array}{l}\text { Psychological and Supportive } \\
\text { Barriers }\end{array}$} & - Disappointment \\
\hline & - Lack of self-confidence \\
\hline & - Lack of motivation \\
\hline & $\begin{array}{l}\text { - Lack of encouragement and emotional support from } \\
\text { others }\end{array}$ \\
\hline \multirow[t]{4}{*}{ Economic Barriers } & - Cost of regular visits to dietitians \\
\hline & - Cost of sports clubs \\
\hline & - Cost of supplements and slimming devices \\
\hline & - Cost of dietary items \\
\hline
\end{tabular}




\section{Results :}

Anthropometric and demographic information participants are presented in Tables 2 and 3, respectively .

A total of 1429 initial codes were obtained from FGDs, and after categorizing, four main barriers were resulted (Table 4). The more repeated barriers were identified as main barriers and each of them has some subgroups.

Our FGDs participants pointed to some barriers categorized as dietary barriers. This group of barriers was the most mentioning barrier claimed by them; it included some subgroups such as food taste, diet and satiety, duration of effect, hard-to-follow and health problems. They pointed to restrictions imposed by the diets like restricted access to specific foods and the fact that the diets were not based on their taste and interests. It was believed that dealing with these problems whilst on weight loss diet, was the reason for failing to follow the diet. In response to the question "Do you think weight loss diets are desirable in terms of taste, fill fullness and diversity?" a woman said: "While on diet, I always feel hungry thus I cannot follow my diet ". Another women in response to a question about disadvantages of weight loss diets said: "It takes a lot of time- that a diet works". A young woman in response to the question "Do you think longterm follow-up to weight loss regimens has health implications?" replied: "While on diet, my body gets weak, and I get sick too often, as if my immune system is getting weaker ".

The second barrier which mentioned by the participants was social and cultural barriers. Participants indicated the lack of social facilities and lack of knowledge about obesity in society cause they left the diet. Role of party or traveling and maternal role were commonly mentioned factors that are threatening weight loss efforts. They also indicated that while they are on diet, their learning and studying ability was reduced and they cannot manage their diet program at work. Women in response to a question about the psychological support of the society :"Obese adolescents are not accepted in the community but no one supports me while I am on a diet ". A woman told about the impact of her social role, as a mother, on the weight loss diet: "When I leave the table sooner before others, my children also follow me and do not eat all their meals".

The third barrier was psychological and supportive barriers. The participants stated that obesity caused many psychological problems, including lack of self-esteem and dissatisfaction .furthermore, the need for mental support and encouragement by family and friends was called by individuals as a stimulant factor. One of the women in response to a question about psychological support of family and friends: "No one helps me or encourages me to follow my dietary programs, and I cannot do it without others' encouragement".

The last barrier which indicated by the participants was economic barriers. economic problems and food costs and cost of regular visits were mentioned as a main barrier to maintain their diet. Participants believed that attending in gyms and providing dietary foods, cost a lot and they are not able to provide these items. 
Women answered to a question about economic conditions :" each visit's price is too much for me and I have to go to the clinic on a weekly basis " and "After the first few weeks, gradually I feel that the price of dietary items puts some pressure on me and I cannot afford it".

Each of seven key informants separately answered questions in 20-30 minute sessions. They pointed out four main barriers and according to their expertise present different aspect of each barrier in Table 5( at the end of the manuscript). 
Table 5

Second- and first-level barrier themes identified through thematic analysis in seven in-depth interview Main barriers Quotation from key informants in, in-depth interviews

Dietary Barriers

-" Observing all aspects of the diet, including diversity, taste and satiety in setting dietary programs ".(nutritionist)

."Mental preparation of individuals priors to lifestyle change". ( sociologist)

•" The prescribed diets should be advantageous and cause no harm to individuals lifestyle". ( psychologist)

- "The inadequacy of the diets to suppress the appetite for fatty foods". (obese woman)

Social and Cultural Barriers
- "The impact of job conditions such as working hours, tasks and other coworkers on following the dietary program". ( nutritionist)

- "Being employed and having a job to work out of the house is a positive factor for individuals to follow their dietary program ". ( sociologist)

- "The positive impact of higher social, occupational and educational status on further efforts to maintain the diet ". ( psychologist)

- "The positive impact of social conditions on motivation along with negative effects

and job constraints ". (obese woman )

Psychological and Supportive Barriers

- "Receiving support and encouragement from surrounding people to develop a positive attitude in individuals ".(nutritionist )

- "Improving the quality of the community in terms of social health and healthy behaviors". ( sociologist)

- "Receiving support for achieving the desired condition avoiding failure and subsequent complications". ( psychologist)

-" Need for cooperation from other family members in order to make weight loss easier ". ( obese woman )

Economic Barriers items ". (nutritionist)

- "Improving the knowledge of dietitians in order to prescribe based on the financial situation of the client". (sociologist)

." Adopting the dietary program with the financial situation of the clients". (Psychologist).

- "Need for sufficient financial support in order to follow a dietary program". (Obese women).

REFRENCE :

1. Baldoni NR, Aquino JA, Alves GC, Sartoreli DS, Franco LJ, Madeira SP, Dal Fabbro AL. Prevalence of overweight and obesity in the adult indigenous population in Brazil: a systematic review with metaanalysis. Diabetes \& Metabolic Syndrome: Clinical Research \& Reviews. 2019 Mar 19. 
2. world Health Organization data and statistics(2020) The challenge of obesity - quick statistics. Available at : http://www.euro.who.int/en/health-topics/noncommunicable-diseases/obesity/dataand-statistics.

3. Janghorbani M, Amini M, Willett WC, Gouya MM, Delavari A, Alikhani S, Mahdavi A. First nationwide survey of prevalence of overweight, underweight, and abdominal obesity in Iranian adults. Obesity. 2007 Nov; $15(11): 2797-808$.

4. Zevin B, Dalgarno N, Martin M, Grady C, Matusinec J, Houlden R, Birtwhistle R, Smith K, Morkem R, Barber D. Barriers to accessing weight-loss interventions for patients with class II or III obesity in primary care: a qualitative study. CMAJ open. 2019 Oct;7(4):E738.

5. Bayati M. Physical inactivity and sedentary lifestyle. Iranian Journal of Endocrinology and Metabolism. 2012 Jan 15;13(5):537-9.

6. Teixeira PJ, Silva MN, Coutinho SR, Palmeira AL, Mata J, Vieira PN, Carraça EV, Santos TC, Sardinha LB. Mediators of weight loss and weight loss maintenance in middle-aged women. Obesity. 2010 Apr;18(4):725 - 35.

7. Ogden $\mathrm{J}$, Clementi $\mathrm{C}$. The experience of being obese and the many consequences of stigma. Journal of obesity. 2010 Mar 25;2010.

8. Ogden J, Sidhu S. Adherence, behavior change, and visualization: a qualitative study of the experiences of taking an obesity medication. Journal of psychosomatic research. 2006 Oct $1 ; 61(4): 545-52$.

9. Nakade M, Aiba N, Morita A, Miyachi M, Sasaki S, Watanabe S. What behaviors are important for successful weight maintenance?. Journal of obesity. 2012 Feb 22;2012.

10. Sharifi N, Mahdavi R, Ebrahimi-Mameghani M. Perceived barriers to weight loss programs for overweight or obese women. Health promotion perspectives. 2013;3(1):11.

11. Perry RA, Daniels LA, Bell L, Magarey AM. Facilitators and Barriers to the Achievement of Healthy Lifestyle Goals: Qualitative Findings FromÂ Australian Parents Enrolled in the PEACH Child Weight Management Program. Journal of nutrition education and behavior. 2016.

12. Flodgren G, Gonçalves-Bradley DC, Summerbell CD. Interventions to change the behaviour of health professionals and the organisation of care to promote weight reduction in children and adults with overweight or obesity. Cochrane Database of Systematic Reviews. 2017(11).

13. Amiri P, Ghofranipour F, Ahmadi FA, Hooman H, Hosseinpanah F, Jalali-Farahani S. Personal barriers to life style modification in overweight/obese adolescents: a qualitative study. Iranian Journal of Endocrinology and Metabolism. 2009;11(5):521-601.

14. Kearney JM, McElhone S. Perceived barriers in trying to eat healthier-results of a pan-EU consumer attitudinal survey. British Journal of Nutrition. 1999 Jun;81(S1):S133-7.

15. López-Azpiazu I, Martínez-González MÁ, Kearney J, Gibney M, Martinez JA. Perceived barriers of, and benefits to, healthy eating reported by a Spanish national sample. Public health nutrition. 1999 Feb;2(2):209 - 15.

16. Rosengren A, Lissner L. The sociology of obesity. InObesity and metabolism 2008 (Vol. 36, pp. 260-270). Karger Publishers. 
17. Coe WH, Redmond L, Parisi JM, Bowie JV, Liu EY, Ng TY, Onyuka AM, Cort M, Cheskin LJ. Motivators, barriers, and facilitators to weight loss and behavior change among African American adults in Baltimore City: A qualitative analysis. Journal of the National Medical Association. 2017 Jun $1 ; 109(2): 79-85$.

18. Kaveh $\mathrm{O}$, Peyrovi $\mathrm{H}$. Exploring Iranian obese women's perceptions of barriers to and facilitators of self-management of obesity: A qualitative study. Journal of Family Medicine and Primary Care. 2019 Nov;8(11):3538.

19. Alm M, Soroudi N, Wylie-Rosett J, Isasi CR, Suchday S, Rieder J, Khan U. A qualitative assessment of barriers and facilitators to achieving behavior goals among obese inner-city adolescents in a weight management program. The Diabetes Educator. 2008 Mar;34(2):277 - 84.

20. Hammarström A, Wiklund AF, Lindahl B, Larsson C, Ahlgren C. Experiences of barriers and facilitators to weight-loss in a diet intervention-a qualitative study of women in Northern Sweden. BMC women's health. 2014 Dec 1;14(1):59.

21. Sobal J. Social and cultural influences on obesity. International textbook of obesity. $2001 \mathrm{Apr}$ $1: 305-22$.

22. Lanoye A, Grenga A, Leahey TM, LaRose JG. Motivation for weight loss and association with outcomes in a lifestyle intervention: comparing emerging adults to middle aged adults. Obesity science \& practice. 2019 Feb;5(1):15-20.

23. Park A, West DS. Understanding socio-cultural factors related to obesity: Sentiment analysis on related tweets. Online Journal of Public Health Informatics. 2019;11(1).

24. Pestoni G, Krieger JP, Sych JM, Faeh D, Rohrmann S. Cultural differences in diet and determinants of diet quality in Switzerland: results from the national nutrition survey menuCH. Nutrients. 2019 Jan;11(1):126.

25. Robertson A, Mullan B, Todd J. A qualitative exploration of experiences of overweight young and older adults. An application of the integrated behaviour model. Appetite. 2014 Apr 1;75:157-64.

26. Greaney ML, Less FD, White AA, Dayton SF, Riebe D, Blissmer B, Shoff S, Walsh JR, Greene GW. College students' barriers and enablers for healthful weight management: a qualitative study. Journal of nutrition education and behavior. 2009 Jul 1;41(4):281-6.

\section{Discussion:}

According to the results of current study, several restrictions like dietary, social and cultural, psychological and supportive and economic barriers were the most barriers to weight loss programs. These barriers have been mentioned by some studies with the same issues $(11,12)$.

The first barrier was related to diet and in this regard, they referred to the lack of attention of dietitians to the particular conditions of each individual, such as family situations, occupation, and they also mentioned the effects of diet on their physical and mental health. Moreover, they considered it unreasonable to change their cooking style based on the dietary recommendations. 
According to Amiri et al., adolescents who participated in a survey in 2010 complained about inadequate knowledge of the nutritionist and the low efficiency of their services (13). Kreany et al., also mentioned the problems regarding the flavor and taste of prescribed diets (14). In addition Lopez et al. reported some barriers, such as mismatch between the diet schedule and working timetable, and unappealing food in the diet programs (15).

Obesity is believed to be widespread in the lower social classes; however, there are various relationships in socioeconomic status and obesity between countries at different stages of development (16). The presence of women in social fields was stated as a positive factor for success in weight-loss programs. According to the viewpoint of our subjects, being employed as well as spending a lot of time out of home increased their sensitivity to their appearance and health. Besides, they stated in details about their role as mothers and its effects on following their diets, and they believed that being a mother could disrupt their focus on the program. (17). Similar to our study, female subjects in other communities have faced problems such as unsafe environments and time limitation for physical activity (18). Conversely, female participants in other studies pointed out the positive aspects of having jobs in following the diet, such as their income for using the health services and sport clubs (19). It has been proven that employed women are less likely to become obese and overweight than non-employed women (20).

The psychological and supportive issues were among the third group of barriers mentioned by our subjects. They emphasized the need for proper social support from people at various levels of society. Besides, they believed that following diet programs was accompanied by some degrees of emotional problems such as fatigue, discouragement and decreased self-esteem, and all participants indicated that these issues could be addressed if they were supported by other peoples. Sobal et al., reported that others behavior could affect the type, amount and timing of food consumption (21) According to Hammarström et al., it could be difficult to match the dietary habits ,including the type, composition and timing of food consumption with other members of the family or other relatives (20). In Alm et al. survey, female subjects believed that psychological support from people around them, such as family members, friends or tutors, was very effective in following the diet programs (19) Some studies indicated that feeling embarrassed at parties, lack of support from friends and family members, and dissatisfaction with the diet in the family and friends gathering all were barriers to the therapeutic diet $(22,23,24)$.

Economic barrier was considered as the last barrier to weight control by our participants. Our participants explained various aspects of the economic barrier, including the cost of monthly visits of dietitians, purchase of dietary items, and attending sports clubs. Several studies highlighted the high cost of providing healthy foods as an economic barrier, and indicated the emphasis of dietitians on a group of some specific food items such as meat, dairy and vegetables caused some individuals not to be able to follow the dietary programs for a long time $(19,25)$. Furthermore, similar to our participants' comments, health practitioners in Woodruff et al. study indicated the lack of sufficient financial resources was a barrier for individuals to refer to nutritionists (26).

\section{Conclusion:}


The participants pointed to four main barriers regarding weight management programs. The included diet related, social, cultural, psychological/ supportive, and economic barriers. The results of this study confirm the key role of the dietitians in designing a proper diet. Furthermore, the supportive role of, the families and, friends in living a healthy life style should not be ignored.

\section{Abbreviations}

FGD :focus group discussions

WHO world health organization

\section{Declarations}

- Ethics approval and consent to participate:

This study was approved by the Shiraz University of Medical Science. According to SUMS legislation, approval from the ethics committee isn't requiring for qualitative studies. All participants provided written informed consent prior to enrolment in the study.

- Consent for publication :

Not applicable

- Competing interests

The authors declare that they have no competing interest.

- Funding

This article was supported with grant number $94-01-84-10515$ by Shiraz University of Medical Sciences which paid for the gifts given to the participants and two note-takers.

- Authors' contributions

ShF : conception and design the study, supervised the research

M B : performed focus groups, analyzed data, co-wrote the paper

M A : design the study, co-wrote the paper, supervised the research

All authors have read and approve the manuscript.

- Acknowledgements 
This article was supported with grant number 94-01-84-10515 by Shiraz University of Medical Sciences. We thank Nadia Razmjuei and Zahra Moein that helped us in this study. Special thanks go to the participants for their kind cooperation.

- Availability of data and materials

The datasets used and/or analyzed during the current study are available from the corresponding author on reasonable request.

\section{References}

1. Baldoni NR, Aquino JA, Alves GC, Sartoreli DS, Franco LJ, Madeira SP, Dal Fabbro AL. Prevalence of overweight and obesity in the adult indigenous population in Brazil: a systematic review with metaanalysis. Diabetes \& Metabolic Syndrome: Clinical Research \& Reviews. 2019 Mar 19.

2. world Health Organization data and statistics(2020) The challenge of obesity - quick statistics. Available at : http://www.euro.who.int/en/health-topics/noncommunicable-diseases/obesity/dataand-statistics.

3. Janghorbani M, Amini M, Willett WC, Gouya MM, Delavari A, Alikhani S, Mahdavi A. First nationwide survey of prevalence of overweight, underweight, and abdominal obesity in Iranian adults. Obesity. 2007 Nov;15(11):2797-808.

4. Zevin B, Dalgarno N, Martin M, Grady C, Matusinec J, Houlden R, Birtwhistle R, Smith K, Morkem R, Barber D. Barriers to accessing weight-loss interventions for patients with class II or III obesity in primary care: a qualitative study. CMAJ open. 2019 Oct;7(4):E738.

5. Bayati M. Physical inactivity and sedentary lifestyle. Iranian Journal of Endocrinology and Metabolism. 2012 Jan 15;13(5):537-9.

6. Teixeira PJ, Silva MN, Coutinho SR, Palmeira AL, Mata J, Vieira PN, Carraça EV, Santos TC, Sardinha LB. Mediators of weight loss and weight loss maintenance in middle-aged women. Obesity. 2010 Apr;18(4):725-35.

7. Ogden J, Clementi C. The experience of being obese and the many consequences of stigma. Journal of obesity. 2010 Mar 25;2010.

8. Ogden J, Sidhu S. Adherence, behavior change, and visualization: a qualitative study of the experiences of taking an obesity medication. Journal of psychosomatic research. 2006 Oct 1;61(4):545-52.

9. Nakade M, Aiba N, Morita A, Miyachi M, Sasaki S, Watanabe S. What behaviors are important for successful weight maintenance?. Journal of obesity. 2012 Feb 22;2012.

10. Sharifi N, Mahdavi R, Ebrahimi-Mameghani M. Perceived barriers to weight loss programs for overweight or obese women. Health promotion perspectives. 2013;3(1):11. 
11. Perry RA, Daniels LA, Bell L, Magarey AM. Facilitators and Barriers to the Achievement of Healthy Lifestyle Goals: Qualitative Findings FromÂ Australian Parents Enrolled in the PEACH Child Weight Management Program. Journal of nutrition education and behavior. 2016.

12. Flodgren G, Gonçalves-Bradley DC, Summerbell CD. Interventions to change the behaviour of health professionals and the organisation of care to promote weight reduction in children and adults with overweight or obesity. Cochrane Database of Systematic Reviews. 2017(11).

13. Amiri P, Ghofranipour F, Ahmadi FA, Hooman H, Hosseinpanah F, Jalali-Farahani S. Personal barriers to life style modification in overweight/obese adolescents: a qualitative study. Iranian Journal of Endocrinology and Metabolism. 2009;11(5):521-601.

14. Kearney JM, McElhone S. Perceived barriers in trying to eat healthier-results of a pan-EU consumer attitudinal survey. British Journal of Nutrition. 1999 Jun;81(S1):S133-7.

15. López-Azpiazu I, Martínez-González MÁ, Kearney J, Gibney M, Martinez JA. Perceived barriers of, and benefits to, healthy eating reported by a Spanish national sample. Public health nutrition. 1999 Feb;2(2):209-15.

16. Rosengren A, Lissner L. The sociology of obesity. InObesity and metabolism 2008 (Vol. 36, pp. 260270). Karger Publishers.

17. Coe WH, Redmond L, Parisi JM, Bowie JV, Liu EY, Ng TY, Onyuka AM, Cort M, Cheskin LJ. Motivators, barriers, and facilitators to weight loss and behavior change among African American adults in Baltimore City: A qualitative analysis. Journal of the National Medical Association. 2017 Jun 1;109(2):79-85.

18. Kaveh O, Peyrovi H. Exploring Iranian obese women's perceptions of barriers to and facilitators of self-management of obesity: A qualitative study. Journal of Family Medicine and Primary Care. 2019 Nov;8(11):3538.

19. Alm M, Soroudi N, Wylie-Rosett J, Isasi CR, Suchday S, Rieder J, Khan U. A qualitative assessment of barriers and facilitators to achieving behavior goals among obese inner-city adolescents in a weight management program. The Diabetes Educator. 2008 Mar;34(2):277-84.

20. Hammarström A, Wiklund AF, Lindahl B, Larsson C, Ahlgren C. Experiences of barriers and facilitators to weight-loss in a diet intervention-a qualitative study of women in Northern Sweden. BMC women's health. $2014 \operatorname{Dec} 1 ; 14(1): 59$.

21. Sobal J. Social and cultural influences on obesity. International textbook of obesity. 2001 Apr 1:30522.

22. Lanoye A, Grenga A, Leahey TM, LaRose JG. Motivation for weight loss and association with outcomes in a lifestyle intervention: comparing emerging adults to middle aged adults. Obesity science \& practice. 2019 Feb;5(1):15-20.

23. Park A, West DS. Understanding socio-cultural factors related to obesity: Sentiment analysis on related tweets. Online Journal of Public Health Informatics. 2019;11(1).

24. Pestoni G, Krieger JP, Sych JM, Faeh D, Rohrmann S. Cultural differences in diet and determinants of diet quality in Switzerland: results from the national nutrition survey menuCH. Nutrients. 2019 
Jan;11(1):126.

25. Robertson A, Mullan B, Todd J. A qualitative exploration of experiences of overweight young and older adults. An application of the integrated behaviour model. Appetite. 2014 Apr 1;75:157-64.

26. Greaney ML, Less FD, White AA, Dayton SF, Riebe D, Blissmer B, Shoff S, Walsh JR, Greene GW. College students' barriers and enablers for healthful weight management: a qualitative study. Journal of nutrition education and behavior. 2009 Jul 1;41(4):281-6.

\section{Supplementary Files}

This is a list of supplementary files associated with this preprint. Click to download.

- lastt.COREQ.docx 